University of Nebraska - Lincoln

DigitalCommons@University of Nebraska - Lincoln

2010

\title{
Isomer identification and resolution in small gold clusters
}

\author{
Wei Huang \\ Brown University \\ Rhitankar Pal \\ University of Nebraska-Lincoln \\ Lei-Ming Wang \\ Washington State University, Richland \\ Xiao Cheng Zeng \\ University of Nebraska-Lincoln, xzeng1@unl.edu \\ Lai-Sheng Wang \\ Brown University, Providence, Rhode Island
}

Follow this and additional works at: https://digitalcommons.unl.edu/chemzeng

Part of the Chemistry Commons

Huang, Wei; Pal, Rhitankar; Wang, Lei-Ming; Zeng, Xiao Cheng; and Wang, Lai-Sheng, "Isomer identification and resolution in small gold clusters" (2010). Xiao Cheng Zeng Publications. 105.

https://digitalcommons.unl.edu/chemzeng/105

This Article is brought to you for free and open access by the Published Research - Department of Chemistry at DigitalCommons@University of Nebraska - Lincoln. It has been accepted for inclusion in Xiao Cheng Zeng Publications by an authorized administrator of DigitalCommons@University of Nebraska - Lincoln. 


\title{
Isomer identification and resolution in small gold clusters
}

\author{
Wei Huang, ${ }^{1}$ Rhitankar Pal, ${ }^{2}$ Lei-Ming Wang, ${ }^{3}$ Xiao Cheng Zeng, ${ }^{2, a)}$ and \\ Lai-Sheng Wang ${ }^{1, b)}$ \\ ${ }^{1}$ Department of Chemistry, Brown University, Providence, Rhode Island, 02912, USA \\ ${ }^{2}$ Department of Chemistry and Center for Materials and Nanoscience, \\ University of Nebraska-Lincoln, Lincoln, Nebraska 68588, USA \\ ${ }^{3}$ Department of Physics, Washington State University, 2710 University Drive, \\ Richland, Washington 99354, USA
}

(Received 7 December 2009; accepted 6 January 2010; published online 5 February 2010)

\begin{abstract}
A variety of experimental techniques are used to resolve energetically close isomers of $\mathrm{Au}_{7}{ }^{-}$and $\mathrm{Au}_{8}{ }^{-}$by combining photoelectron spectroscopy and ab initio calculations. Two structurally distinct isomers are confirmed to exist in the cluster beam for both clusters. Populations of the different isomers in the cluster beam are tuned using Ar-tagging, $\mathrm{O}_{2}$-titration, and isoelectronic atom substitution by $\mathrm{Cu}$ and $\mathrm{Ag}$. A new isomer structure is found for $\mathrm{Au}_{7}{ }^{-}$, which consists of a triangular $\mathrm{Au}_{6}$ unit with a dangling $\mathrm{Au}$ atom. Isomer-specific photoelectron spectra of $\mathrm{Au}_{8}{ }^{-}$are obtained from $\mathrm{O}_{2}$-titration experiment. The global minimum and low-lying structures of $\mathrm{Au}_{7}{ }^{-}, \mathrm{Au}_{8}{ }^{-}$, and $\mathrm{MAu}_{n}{ }^{-}$ $(n=6,7 ; \mathrm{M}=\mathrm{Ag}, \mathrm{Cu})$ are obtained through basin-hopping global minimum searches. The results demonstrate that the combination of well-designed photoelectron spectroscopy experiments (including Ar-tagging, $\mathrm{O}_{2}$-titration, and isoelectronic substitution) and ab initio calculation is not only powerful for obtaining the electronic and atomic structures of size-selected clusters, but also valuable in resolving structurally and energetically close isomers of nanoclusters. (C) 2010 American Institute of Physics. [doi:10.1063/1.3299292]
\end{abstract}

\section{INTRODUCTION}

The properties of nanoparticles are known to depend on both their size and shape. The discovery of catalytic activities of supported gold nanoparticles ${ }^{1}$ has stimulated intense interests in the structures and properties of gaseous gold clusters, ${ }^{2-7}$ which provide atomically defined models for understanding the mechanisms of the catalytic effects of gold nanoparticles. ${ }^{8}$ Different techniques have been used to probe the structures of gold nanoclusters, including photoelectron spectroscopy (PES), ${ }^{9}$ ion mobility, ${ }^{10,11}$ infrared multiphoton dissociation spectroscopy, ${ }^{12,13}$ and trapped ion electron diffraction. ${ }^{14}$ While all these techniques are quite powerful, in particular, when combined with $a b$ initio calculations in obtaining structural information, the identification and resolution of structurally and energetically close isomers have remained a considerable challenge.

Because of the theoretical difficulties presented by gold clusters as a result of the strong relativistic and spin-orbit effects, ${ }^{15-17}$ definitive experimental data are essential in helping elucidate their structures and chemical reactivity. In particular, in cases of structurally and energetically close isomers, it is critical to be able to identify contributions from different isomers and to obtain isomer-specific chemical and spectroscopic information. A variety of structures have been resolved experimentally and proposed theoretically for a range of gold clusters. The structures of gold cluster anions $\left(\mathrm{Au}_{n}{ }^{-}\right)$in the size range from $n=3$ to 20 have been studied using a combination of experimental techniques and density

\footnotetext{
${ }^{a)}$ Electronic mail: xczeng@phase2.unl.edu.

${ }^{b)}$ Electronic mail: lai-sheng_wang@brown.edu.
}

functional theory (DFT) calculations, ranging from the planar [two-dimensional (2D)] clusters for $n \leq 12,{ }^{10,18-24}$ the tetrahedral $\mathrm{Au}_{20}{ }^{-25}$ and the cage clusters for $n=16-18 . .^{14,26-30}$ Even for relatively small gold clusters, the structures and, particularly, the isomer issues in a few cases still remain questionable and controversial and need more definitive experimental and theoretical evidence to be resolved. $5,13,22,27,31-33$

Recently, we have shown that there are at least four coexisting isomers in the $\mathrm{Au}_{10}{ }^{-}$cluster beam ${ }^{31}$ using Artagging and $\mathrm{O}_{2}$-titration techniques ${ }^{34,35}$ in combination with PES, revealing the structural diversity and complexity of small gold clusters. We have also observed that planar $\mathrm{Au}_{n}{ }^{-}$ clusters, as well as the pyramidal $\mathrm{Au}_{20}{ }^{-}$, have stronger charge-induced intermolecular interactions with $\mathrm{Ar}$, and used this property to obtain isomer-specific PES spectra for $\mathrm{Au}_{12}^{-}$ (Ref. 22) and obtained distinct experimental evidence that the cage-to-pyramid crossover occurs at $\mathrm{Au}_{18}{ }^{-28}$ Although Ar-tagging and $\mathrm{O}_{2}$-titration combined with PES have been proven very useful in resolving isomers of nanoclusters, there are deficiencies under certain circumstances. Artagging is especially useful when the isomers have very different structures, for example, the 2D versus threedimensional (3D) structures in $\mathrm{Au}_{12}{ }^{-22}$. If the isomers have similar structures and thus similar charge-induced intermolecular interactions with Ar, it would be difficult to obtain isomer-specific spectra using the Ar-tagging method. $\mathrm{O}_{2}$-titration cannot be used for those clusters unreactive with $\mathrm{O}_{2}$, such as odd-sized $\mathrm{Au}_{n}{ }^{-}$clusters or isomers with similar $\mathrm{O}_{2}$ reactivity. Ion mobility is especially useful in resolving geometrical structures of nanoclusters according to different 
collision cross sections of different isomers. ${ }^{10,11}$ However, just like Ar-tagging, when two isomers have similar structures or similar collision cross sections, it would be very difficult or impossible to resolve the isomers in ion mobility.

In this article, we report a detailed study of the isomers of $\mathrm{Au}_{7}{ }^{-}$and $\mathrm{Au}_{8}{ }^{-}$using $\mathrm{Ar}$ and $\mathrm{O}_{2}$-tagging, $\mathrm{O}_{2}$-titration, and isoelectronic atom substitution by $\mathrm{Cu}$ and $\mathrm{Ag}$. We show that even for these very small clusters their structural isomers have not been fully understood. Both clusters have been suggested to have multiple isomers in our previous PES study, but not definitively identified. ${ }^{19}$ Here we show that there are two energetically and structurally close isomers for each cluster. In particular, we find a dangling Au atom isomer for $\mathrm{Au}_{7}{ }^{-}$, which is always populated in the cluster beam but has not been recognized. The relative stability of this isomer is found to vary with $\mathrm{Cu}$ or $\mathrm{Ag}$ substitution. Using $\mathrm{O}_{2}$-titration, we are able to obtain isomer-specific photoelectron spectrum of $\mathrm{Au}_{8}{ }^{-}$. The global minima and the low-lying structures of $\mathrm{Au}_{7}{ }^{-}, \mathrm{Au}_{8}{ }^{-}$, and $\mathrm{MAu}_{n}{ }^{-}(\mathrm{M}=\mathrm{Ag}, \mathrm{Cu} ; n=6,7)$ are obtained using basin-hopping searches ${ }^{36-39}$ and their computed densities of states (DOS) are used to compare with the PES data.

\section{METHODS}

\section{A. PES EXPERIMENT}

The experiment was carried with a magnetic bottle PES apparatus equipped with a laser vaporization cluster source, details of which has been reported elsewhere. ${ }^{40}$ A gold disk target (or a gold target doped with $\mathrm{Ag}$ or $\mathrm{Cu}$ ) was vaporized by a pulsed laser to generate a plasma inside a cluster nozzle with a large waiting room. A high-pressure helium carrier gas pulse was delivered to the nozzle simultaneously, cooling the plasma and initiating nucleation. Clusters formed inside the nozzle were entrained in the helium carrier gas and underwent a supersonic expansion for further cooling. After a skimmer, anions from the collimated cluster beam were extracted perpendicularly into a time-of-flight mass spectrometer. Clusters of interest were selected by a mass gate and decelerated before being photodetached by a $193 \mathrm{~nm}(6.424$ eV) laser beam from an ArF excimer laser. Photoelectrons were collected by a magnetic bottle at nearly $100 \%$ efficiency into a 3.5-m-long electron flight tube for kinetic energy analyses. The photoelectron kinetic energies were calibrated by the known spectra of $\mathrm{Au}^{-}$and subtracted from the photon energies to obtain the reported electron binding energy spectra. The electron kinetic energy $\left(\mathrm{E}_{\mathrm{k}}\right)$ resolution of our apparatus is $\Delta \mathrm{E}_{\mathrm{k}} / \mathrm{E}_{\mathrm{k}} \sim 2.5 \%$, i.e., $\sim 25 \mathrm{meV}$ for $1 \mathrm{eV}$ electrons.

As shown previously, ${ }^{41,42}$ by carefully controlling the residence time of the clusters in the nozzle, relatively cold clusters can be produced from our laser vaporization supersonic cluster source. The cooling effects have been confirmed recently by the observation of molecular complexes of gold cluster anions with $\mathrm{Ar}$ and $\mathrm{O}_{2} \cdot{ }^{22,28,31,43}$ In the present study, the $\mathrm{Au}_{7} \mathrm{Ar}_{\mathrm{x}}{ }^{-}$complexes were produced using a helium carrier gas seeded with $5 \%$ Ar. For the $\mathrm{O}_{2}$-tagging experiment, a $0.5 \% \mathrm{O}_{2} / \mathrm{He}$ carrier gas was used. For the $\mathrm{O}_{2}$-titration experiment for $\mathrm{Au}_{8}{ }^{-}$, a $25-\mathrm{mm}$-long and $6 \mathrm{~mm}$ diameter stainless steel reactor was added to the cluster nozzle. The exit of the reactor was reduced to $3 \mathrm{~mm}$ diameter to enhance the reaction time. A hole was drilled in the middle of the reactor for the delivery of reactive gases. In the current study, a $0.5 \% \mathrm{O}_{2} / \mathrm{He}$ reactive gas was pulsed into the reactor for the titration experiment.

\section{B. Theoretical calculations}

The structural searches were done using the basinhopping global minimum search technique coupled with DFT calculations for geometry optimization. Independent searches were performed using basin-hopping programs written by Wei Huang and the University of Nebraska-Lincoln (UNL) group; generalized gradient approximation in the Perdue-Burke-Ernzerhof (PBE) functional form ${ }^{44}$ was chosen in both searches. Several randomly selected initial structures were used for the basin-hopping searches, all lead to consistent sets of low-lying isomers for each cluster anion. The top ten lowest-lying isomers were reoptimized using the PBE0/CRENBL hybrid functional/basis set, as implemented in the NWCHEM 5.1.1 software package. ${ }^{45,46}$ Lastly, relative energies of the top four lowest-lying isomers are computed using the M06-L functional ${ }^{23,24}$ and CRENBL basis set (with inclusion of spin-orbit effects). The results are presented in Figs. S1 and S2 and Tables S1 and S2 of Ref. 47.

To compare with the measured PES spectra, the first vertical detachment energies (VDEs) of the anion clusters were computed (at PBE0/CRENBL level of theory implemented in the NWCHEM 5.1.1, which includes the spin-orbit effects). The binding energies of deeper orbitals were then added to the first VDE to give VDEs for the excited states. Each VDE was fitted with a Gaussian of width $0.035 \mathrm{eV}$ to yield the simulated DOS spectra.

\section{RESULTS AND DISCUSSION}

The photoelectron spectra of $\mathrm{Au}_{n}{ }^{-}(n=7,8)$ and $\mathrm{MAu}_{n}{ }^{-}$ $(\mathrm{M}=\mathrm{Ag}, \mathrm{Cu} ; n=6,7)$ along with the corresponding simulated DOS spectra are presented in Figs. 1-4, respectively. The theoretical and experimental VDEs are compared in Table I.

Different anion isomers have different charge-induced intermolecular interactions with $\mathrm{Ar}^{43}$ Thus, the relative populations of different isomers can change in the cluster $\mathrm{Ar}$ complexes. $^{22}$ Figure 1(a) shows that the relative intensities of the second peak $\left(\mathrm{X}^{\prime}\right)$ and several other peaks in the spectra of $\mathrm{Au}_{7} \mathrm{Ar}^{-}$(blue curve) are slightly reduced as compared to those of pure $\mathrm{Au}_{7}{ }^{-}$(red curve), indicating that these peaks likely come from a different (minor) isomer, whose interaction with $\mathrm{Ar}$ is weaker than that between the major isomer of $\mathrm{Au}_{7}{ }^{-}$and Ar. Furthermore, $\mathrm{Au}_{7}{ }^{-}$does not react with $\mathrm{O}_{2}$. However, we found that $\mathrm{O}_{2}$ can physisorb onto $\mathrm{Au}_{7}{ }^{-}$, providing the possibility for $\mathrm{O}_{2}$-tagging. ${ }^{28}$ Indeed, we see that the PES spectra of $\mathrm{Au}_{7}\left(\mathrm{O}_{2}\right)^{-}$[Fig. 1(b)] and $\mathrm{Au}_{7} \mathrm{Ar}^{-}$are very similar. The observed differences between the PES spectra of $\mathrm{Au}_{7}{ }^{-}$and $\mathrm{Ar} / \mathrm{O}_{2}$-tagged $\mathrm{Au}_{7}{ }^{-}$are very small; the observation provides experimental hints that there are more than one isomer in the cluster beam.

To provide further evidence about the isomers of $\mathrm{Au}_{7}{ }^{-}$, we substituted one $\mathrm{Au}$ atom by a $\mathrm{Ag}$ or $\mathrm{Cu}$ atom. These isoelectronic substitutions can alter the relative stabilities of 


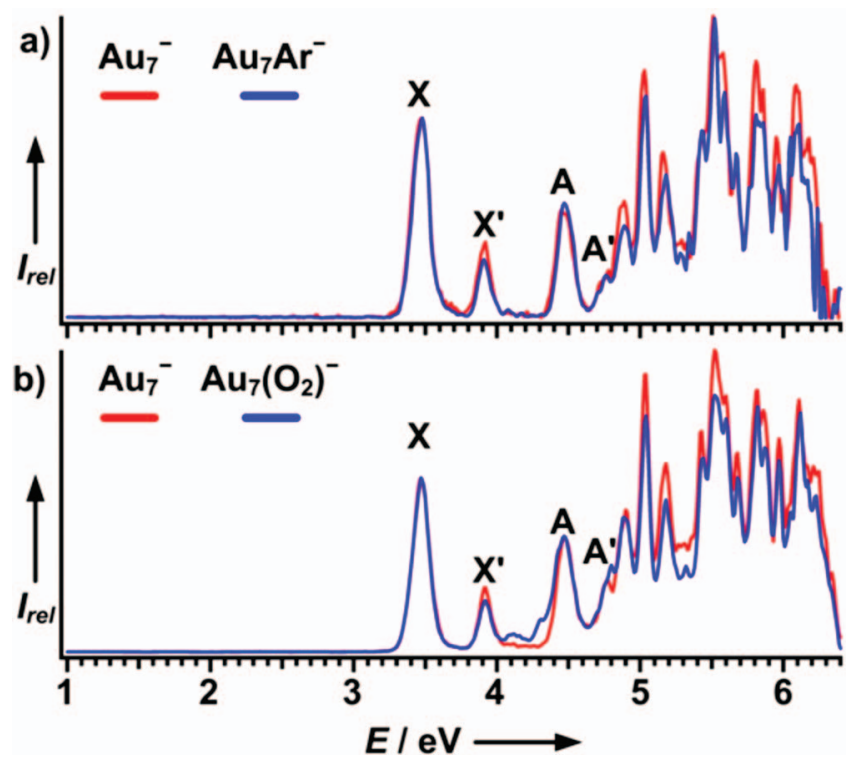

FIG. 1. The $193 \mathrm{~nm}(6.424 \mathrm{eV})$ photoelectron spectra of (a) $\mathrm{Au}_{7}{ }^{-}$and $\mathrm{Au}_{7} \mathrm{Ar}^{-}$using a $\mathrm{He}$ carrier gas seeded with $1 \%-3 \% \mathrm{Ar}$ and (b) $\mathrm{Au}_{7}^{-}$and $\mathrm{Au}_{7} \mathrm{O}_{2}{ }^{-}$using a $\mathrm{He}$ carrier gas seeded with $0.5 \% \mathrm{O}_{2}$.

the isomers, thereby their relative populations in the cluster beams. Indeed, the PES spectra of $\mathrm{AgAu}_{6}{ }^{-}$[Fig. 2(b)] and $\mathrm{CuAu}_{6}{ }^{-}$[Fig. 2(c)] show remarkable similarities to that of undoped $\mathrm{Au}_{7}{ }^{-}$, except that the relative intensities of different peaks are changed. In particular, the relative intensity of the $\mathrm{X}^{\prime}$ peak increased substantially, while those of the $\mathrm{X}$ and $\mathrm{A}$ peaks decreased. The A peak of $\mathrm{AgAu}_{6}{ }^{-}$is overlapped with the $\mathrm{A}^{\prime}$ peak [Fig. 2(b)], but it is clear that the relative ratios of the $\mathrm{X}$ and $\mathrm{A}$ peaks are unchanged, suggesting that they come from one isomer, and this isomer is similar to the main isomer of $\mathrm{Au}_{7}^{-}$. The $\mathrm{X}^{\prime}$ and $\mathrm{A}^{\prime}$ peaks increased in both the spectra of $\mathrm{AgAu}_{6}{ }^{-}$and $\mathrm{CuAu}_{6}{ }^{-}$proportionally, and they are similar to the $\mathrm{X}^{\prime}$ and $\mathrm{A}^{\prime}$ peaks in $\mathrm{Au}_{7}^{-}$, suggesting that this isomer becomes the dominant species in the doped clusters.

To identify the two isomers, we performed basinhopping global minimum searches combined with DFT calculations on $\mathrm{Au}_{7}{ }^{-}, \mathrm{AgAu}_{6}{ }^{-}$, and $\mathrm{CuAu}_{6}{ }^{-}$from randomly generated initial structures. It should be pointed out that two independent basin-hopping searches ${ }^{36,37}$ on $\mathrm{Au}_{7}{ }^{-}$were per-

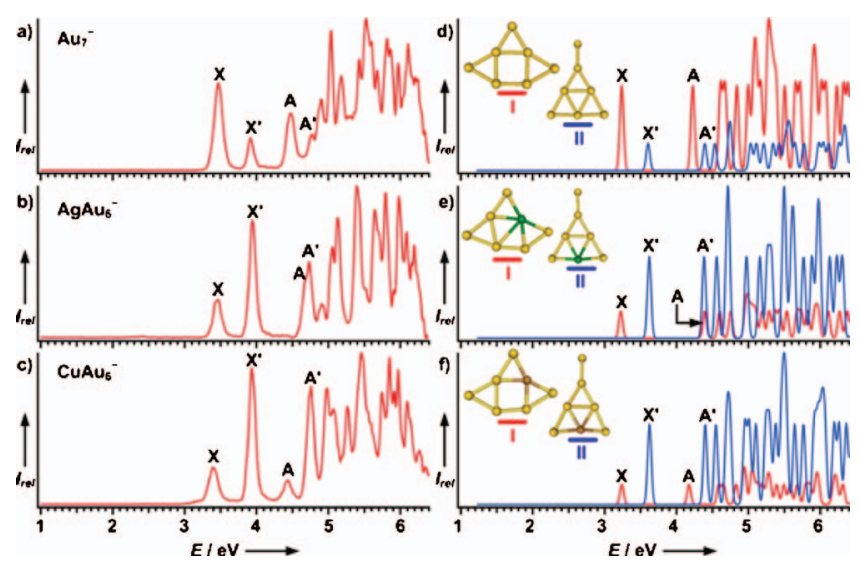

FIG. 2. Left panel: $193 \mathrm{~nm}$ experimental photoelectron spectra of (a) $\mathrm{Au}_{7}{ }^{-}$, (b) $\mathrm{AgAu}_{6}{ }^{-}$, and (c) $\mathrm{CuAu}_{6}{ }^{-}$. Right panel: Structures and simulated DOS spectra of isomers I and II for (d) $\mathrm{Au}_{7}{ }^{-}$, (e) $\mathrm{AgAu}_{6}{ }^{-}$, and (f) $\mathrm{CuAu}_{6}{ }^{-}$.
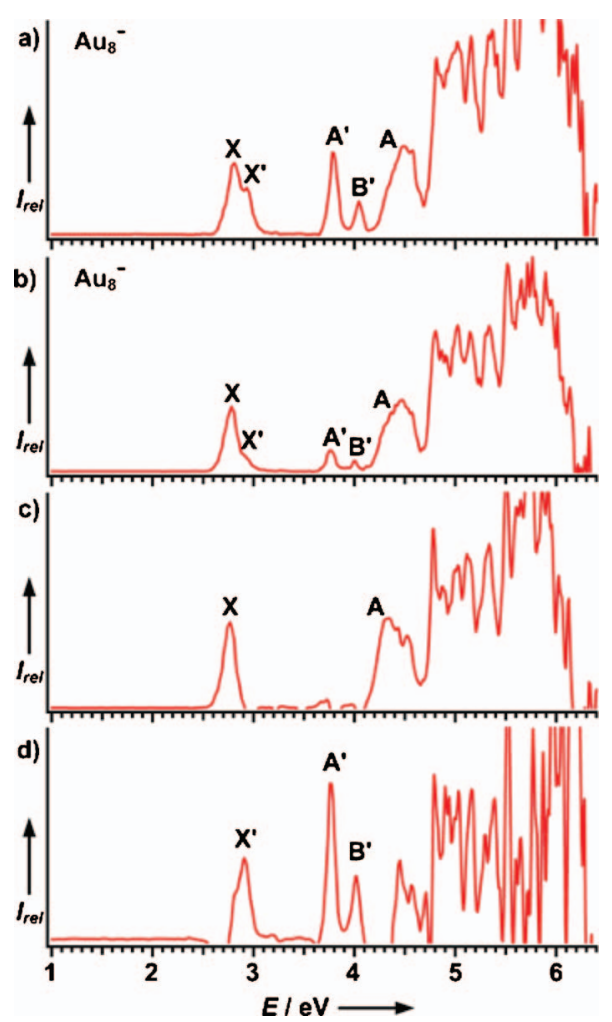

FIG. 3. Photoelectron spectra of $\mathrm{Au}_{8}{ }^{-}$. (a) Using pure He carrier gas; (b) using a $5 \% \mathrm{O}_{2} / \mathrm{He}$ reactant gas with the flow tube reactor; (c) the spectrum of the $\mathrm{D}_{4 \mathrm{~b}}$ isomer obtained by subtracting (d) from (b); and (d) the spectrum of the $\mathrm{C}_{2 \mathrm{v}}$ isomer obtained by subtracting (b) from (a).

formed in the current study, one by a program written by one of the coauthors (W. H.) and another by the UNL group. A dangling $\mathrm{Au}$ atom isomer of $\mathrm{Au}_{7}^{-}$was found independently using both programs. The basin-hopping searches of the $\mathrm{Au} / \mathrm{Ag}$ and $\mathrm{Au} / \mathrm{Cu}$ binary clusters were performed solely by the UNL group. ${ }^{38,39}$ The top ten low-lying isomers were reoptimized and relative energies of four low-lying isomers are presented in Fig. S1. ${ }^{47}$ Except $\mathrm{CuAu}_{6}^{-}$, we found that the 2D planar isomers are appreciably lower in energy than the $3 \mathrm{D}$ isomers (Fig. S1). ${ }^{47}$ The lowest-energy isomer of $\mathrm{CuAu}_{6}{ }^{-}$has a 3D structure. However, the computed DOS spectrum

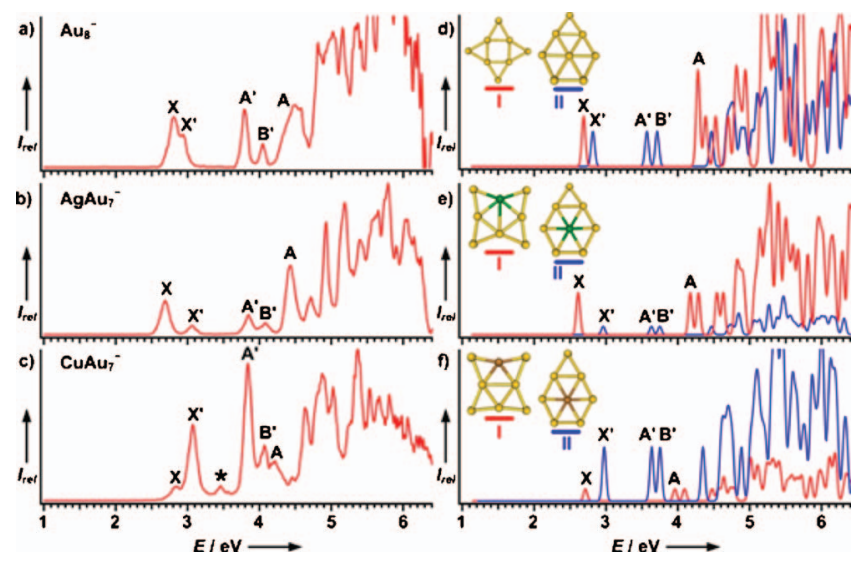

FIG. 4. Left panel: $193 \mathrm{~nm}$ photoelectron spectra of (a) $\mathrm{Au}_{8}{ }^{-}$, (b) $\mathrm{AgAu}_{7}{ }^{-}$, and (c) $\mathrm{CuAu}_{7}{ }^{-}$. Right panel: The structures and simulated DOS spectra of isomers I and II for (d) $\mathrm{Au}_{8}{ }^{-}$, (e) $\mathrm{AgAu}_{7}{ }^{-}$, and (f) $\mathrm{CuAu}_{7}{ }^{-}$. 
TABLE I. The measured VDEs compared to calculated VDEs for the isomers of the pure gold clusters $\mathrm{Au}_{7}{ }^{-}$and $\mathrm{Au}_{8}{ }^{-}$, and the doped clusters $\mathrm{MAu}_{6}{ }^{-}$ and $\mathrm{MAu}_{7}^{-}(\mathrm{M}=\mathrm{Ag}, \mathrm{Cu})$. All energies are in electron volts.

\begin{tabular}{|c|c|c|}
\hline & \multicolumn{2}{|c|}{$\begin{array}{l}\text { VDE } \\
(\mathrm{eV})\end{array}$} \\
\hline & Expt. $^{a}$ & Theor. $^{\mathrm{b}}$ \\
\hline $\mathrm{Au}_{7}^{-}(\mathrm{I})$ & $3.46(2)^{\mathrm{c}}$ & 3.24 \\
\hline $\mathrm{Au}_{7}^{-}$(II) & $3.92(3)$ & 3.61 \\
\hline $\mathrm{AgAu}_{6}^{-}(\mathrm{I})$ & $3.45(4)$ & 3.22 \\
\hline $\mathrm{AgAu}_{6}^{-}$(II) & $3.94(3)$ & 3.62 \\
\hline $\mathrm{CuAu}_{6}^{-}{ }^{-}(\mathrm{I})$ & $3.40(4)$ & 3.24 \\
\hline $\mathrm{CuAu}_{6}{ }^{-}$(II) & $3.94(3)$ & 3.62 \\
\hline $\mathrm{Au}_{8}^{-}\left(\mathrm{I}, \mathrm{D}_{4 \mathrm{~h}}\right)$ & $2.79(2)^{\mathrm{c}}$ & 2.69 \\
\hline $\mathrm{Au}_{8}^{-}\left(\mathrm{II}, \mathrm{C}_{2 \mathrm{v}}\right)$ & 2.91(4) & 2.82 \\
\hline $\mathrm{AgAu}_{7}^{-}$(I) & $2.69(4)$ & 2.61 \\
\hline $\mathrm{AgAu}_{7}^{-}$(II) & $3.06(4)$ & 2.96 \\
\hline $\mathrm{CuAu}_{7}^{-}(\mathrm{I})$ & $2.83(4)$ & 2.71 \\
\hline $\mathrm{CuAu}_{7}^{-}$(II) & $3.07(4)$ & 2.97 \\
\hline
\end{tabular}

${ }^{\mathrm{a}}$ Numbers in parentheses represent the uncertainty in the last digit.

${ }^{\mathrm{b}}$ Theoretical VDE is always smaller than the experimental VDE by $0.1-0.3 \mathrm{eV}$ when spin-orbit effects are included in PBE0/CRENBL level calculation.

${ }^{\mathrm{c}}$ Taken from Ref. 19.

[Fig. S1(i)] (Ref. 47) of this 3D isomer is markedly different from the measured PES spectrum, and thus can be ruled out.

The lowest-energy isomer of $\mathrm{Au}_{7}^{-}$is the same as reported before. ${ }^{10,18,19}$ The low-lying isomer of $\mathrm{Au}_{7}{ }^{-}$, a dangling $\mathrm{Au}$ atom structure (coordinates of this isomer is given in Table S1), ${ }^{47}$ can be viewed by simply attaching the extra atom to an apex site of the very stable $\mathrm{D}_{3 \mathrm{~h}} \mathrm{Au}_{6}{ }^{-}$cluster. It is remarkable that this isomer was missed in all previous studies on $\mathrm{Au}_{7}^{-}$(note that the isomer 7B reported in Ref. 19 is not a local minimum based on the PBE0/CRENBL calculation). The two lowest-lying 2D planar isomers of $\mathrm{AgAu}_{6}{ }^{-}$ and $\mathrm{CuAu}_{6}{ }^{-}$have nearly the same structures as those of $\mathrm{Au}_{7}{ }^{-}$, except that the dangling $\mathrm{Au}$ atom structure becomes the lowest-energy 2D structure rather than the second lowestenergy 2D structure (Fig. S1). ${ }^{47}$ This change in relative stabilities between the two lowest-lying isomers corroborates with the change in relative populations in the cluster beams, as demonstrated by the substantial change in the relative intensity between the $\mathrm{X}^{\prime}$ peak and the $\mathrm{X}$ peak [Figs. 2(a)-2(c)].

In $\mathrm{MAu}_{6}{ }^{-}(\mathrm{M}=\mathrm{Ag}, \mathrm{Cu})$, the $\mathrm{Ag}$ or $\mathrm{Cu}$ atom seems to prefer the site with more coordination in both isomers and to stay away from the dangling Au atom [Figs. 2(e) and 2(f) and Table S1 (Ref. 47)]. To compare with the experimental data, we computed the DOS spectra by including the relativistic and spin-orbit effects for several lowest-lying isomers. As shown in Fig. 2, the simulated DOS spectra for the two lowest-lying 2D isomers of $\mathrm{Au}_{7}{ }^{-}, \mathrm{AgAu}_{6}^{-}$, and $\mathrm{CuAu}_{6}{ }^{-}$are in quantitative agreement with the experimental data, providing considerable credence for the identified isomers for these clusters.

It is interesting to understand why the difference between the spectra of $\mathrm{Au}_{7}{ }^{-}$and $\mathrm{Au}_{7} \mathrm{Ar}^{-}$is small compared to the difference observed previously between the spectra of $\mathrm{Au}_{12}^{-}$and $\mathrm{Au}_{12} \mathrm{Ar}^{-}{ }^{22}$ This is due to the fact that the two isomers of $\mathrm{Au}_{12}{ }^{-}$are $2 \mathrm{D}$ and $3 \mathrm{D},{ }^{10}$ respectively, and, therefore, have very different intermolecular interactions with $\mathrm{Ar}$, while both isomers of $\mathrm{Au}_{7}{ }^{-}$are 2D and have similar intermolecular interactions with Ar.

We also attempted Ar-tagging on $\mathrm{Au}_{8}{ }^{-}$, but the spectra of $\mathrm{Au}_{8} \mathrm{Ar}^{-}$and $\mathrm{Au}_{8}{ }^{-}$are nearly identical and cannot be used to distinguish contributions from different isomers. $\mathrm{Au}_{8}{ }^{-}$is reactive with $\mathrm{O}_{2}$, providing an opportunity to carry out $\mathrm{O}_{2}$-titration. ${ }^{27,28}$ We have built a fast flow cluster reactor, which consists of a 25 -mm-long and $6 \mathrm{~mm}$ diameter stainless steel tube attached to the cluster source nozzle. Reactant gases $\left(\mathrm{O}_{2}\right.$ here $)$ can be introduced through a hole drilled in the middle of the stainless steel tube. A cap with a $3 \mathrm{~mm}$ hole is installed at the exit of the tube to increase the residence time of the reactant. By using a 5\% $\mathrm{O}_{2} / \mathrm{He}$ reactant gas, we obtained the $\mathrm{Au}_{8}{ }^{-}$spectrum, as shown in Fig. 3(b). This spectrum is quite different from that using pure He carrier gas[Fig. 3(a)] that we reported previously. ${ }^{19}$ Specifically, the relative intensities of the $\mathrm{X}^{\prime}, \mathrm{A}^{\prime}$, and $\mathrm{B}^{\prime}$ peaks decreased dramatically, suggesting that they come from an isomer that has been titrated out of the cluster beam. The ground state of $\mathrm{Au}_{8}{ }^{-}$is known to be of a $\mathrm{D}_{4 \mathrm{~h}}$ structure and its low-lying isomer is a $\mathrm{C}_{2 \mathrm{v}}$ structure [Fig. 4(d)]. ${ }^{10,19}$ Clearly, the lowlying $\mathrm{C}_{2 \mathrm{v}}$ isomer, which corresponds to the $\mathrm{X}^{\prime}, \mathrm{A}^{\prime}$ and $\mathrm{B}^{\prime}$ peaks, is titrated out of the cluster beam. Since Fig. 3(b) contains very little contribution from the $\mathrm{C}_{2 \mathrm{v}}$ isomer, this spectrum is subtracted from Fig. 3(a) to yield the isomerspecific spectrum for the $\mathrm{C}_{2 \mathrm{v}}$ isomer, as shown in Fig. 3(d). ${ }^{48}$ The spectrum in Fig. 3(d) is then subtracted from Fig. 3(b) to yield the isomer-specific spectrum for the $\mathrm{D}_{4 \mathrm{~h}}$ structure [Fig. $3(\mathrm{c})]$ by appropriate normalization.

The photoelectron spectra of $\mathrm{Ag} / \mathrm{Cu}$ substituted $\mathrm{Au}_{8}{ }^{-}$are shown in Figs. 4(b) and 4(c). The peak positions of $\mathrm{AgAu}_{7}{ }^{-}$ and $\mathrm{CuAu}_{7}{ }^{-}$are almost the same as that of $\mathrm{Au}_{8}{ }^{-}$, suggesting that the same isomers are present in the spectra of the substituted clusters. However, the relative intensities are changed: the $\mathrm{X}^{\prime}, \mathrm{A}^{\prime}$, and $\mathrm{B}^{\prime}$ peaks become weaker in the

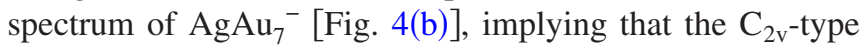
isomer in $\mathrm{AgAu}_{7}{ }^{-}$may become less stable. The same peaks become dominant in the spectrum of $\mathrm{CuAu}_{7}^{-}$[Fig. 4(c)], suggesting that the $\mathrm{C}_{2 \mathrm{v}}$-type isomer may become the global minimum in this system. The weak peak labeled with ${ }^{*}$ in Fig. 4(c) may arise from an unidentified impurity or another minor isomer.

We also performed independent basin-hopping searches for $\mathrm{Au}_{8}{ }^{-}, \mathrm{AgAu}_{7}{ }^{-}$, and $\mathrm{CuAu}_{7}{ }^{-}$. The two lowest-lying structures of each species are shown in Figs. 4(d)-4(f), respectively (coordinates are given in Table S2), ${ }^{47}$ and relative energies of four low-lying isomers are presented in Fig. S2. ${ }^{47}$ The DFT calculation suggests that the $\mathrm{D}_{4 \mathrm{~h}}$ and $\mathrm{C}_{2 \mathrm{v}}$ isomers of $\mathrm{Au}_{8}{ }^{-}$are isoenergetic [Figs. S2(a) and S3(b)] (Ref. 47) and both are candidates of the lowest-energy clusters. ${ }^{10,19}$ The simulated DOS spectra of the two isomers are in excellent agreement with the isomer-specific PES spectra shown in Figs. 3(c) and 3(d), respectively. The next low-lying isomer is much higher in energy than the $\mathrm{D}_{4 \mathrm{~h}}$ and $\mathrm{C}_{2 \mathrm{v}}$ isomers [Fig. S2(c)]. ${ }^{47}$

The two lowest-lying structures of $\mathrm{AgAu}_{7}{ }^{-}$and $\mathrm{CuAu}_{7}{ }^{-}$ are found indeed to be similar to those of $\mathrm{Au}_{8}{ }^{-}$. Again, we 
found that the $\mathrm{Ag}$ and $\mathrm{Cu}$ atoms prefer high coordination sites in $\mathrm{AgAu}_{7}{ }^{-}$and $\mathrm{CuAu}_{7}{ }^{-}$. The simulated DOS spectra for the two isomers of $\mathrm{AgAu}_{7}{ }^{-}$and $\mathrm{CuAu}_{7}{ }^{-}$are also in very good agreement with the experimental data, lending additional credence to the structures identified for the substituted clusters. Moreover, the change in the relative stabilities of the isomers of $\mathrm{CuAu}_{7}^{-}$[Figs. S2(i) and S2(j)] (Ref. 47) is consistent with the major change in relative populations in the cluster beams as demonstrated by the substantial change in the relative intensity of the $X^{\prime}$ peak versus the $X$ peak [Figs. 4(a) and 4(c)]. However, the change in the relative stabilities of the isomers of $\mathrm{AgAu}_{7}^{-}$[Figs. S2(e) and S2(f)] (Ref. 47) is inconsistent with the relatively small change in relative populations in the cluster beams. Perhaps much larger basis sets than the CRENBL or higher-level theories than DFT are needed to resolve this inconsistency.

\section{CONCLUSION}

In conclusion, we report a detailed investigation of the structures and isomers of $\mathrm{Au}_{7}{ }^{-}$and $\mathrm{Au}_{8}{ }^{-}$using a combination of experimental techniques (Ar-tagging, $\mathrm{O}_{2}$-titration, and isoelectronic substitution) in conjunction with basin-hopping global minimum searches. A new isomer is identified for $\mathrm{Au}_{7}{ }^{-}$, which consists of a triangular $\mathrm{Au}_{6}$ unit with a terminal $\mathrm{Au}$ atom. For $\mathrm{Au}_{8}{ }^{-}$, we found that $\mathrm{O}_{2}$-titration can be used to titrate out the second lowest-energy isomer to yield isomerspecific PES spectra. The $\mathrm{Ag}$ and $\mathrm{Cu}$ substituted $\mathrm{Au}_{7}{ }^{-}$and $\mathrm{Au}_{8}{ }^{-}$clusters are shown to possess similar structures and isomers as the parent clusters and the $\mathrm{Ag}$ and $\mathrm{Cu}$ dopant atoms are found to prefer high coordination sites. The current study reveals the structural diversity for even relatively small Au clusters and demonstrates that well-designed PES experiments in combination with ab initio calculations are highly valuable to elucidate the structures and energetics of nanoclusters.

\section{ACKNOWLEDGMENTS}

The experimental work was supported by the U.S. National Science Foundation (Grant No. CHE-0749496). The theoretical work done by W.H. was performed with the supercomputers at the EMSL Molecular Computing Facility of Pacific Northwest National Lab. W.H. thanks Dr. Niranjan Govind, High-Performance Computing Center in EMSL, and the NWCHEM developer team for invaluable help in developing the basin-hopping program. The theoretical work done at Nebraska was supported by grants from the National Science Foundation (Grant No. DMR-0820521), the Nebraska Research Initiative, and the University of Nebraska Holland Computing Center.

\footnotetext{
${ }^{1}$ M. Haruta, Catal. Today 36, 153 (1997).

${ }^{2}$ P. Pyykkö, Chem. Soc. Rev. 37, 1967 (2008).

${ }^{3}$ H. Häkkinen, Chem. Soc. Rev. 37, 1847 (2008).

${ }^{4}$ P. Pyykkö, Nat. Nanotechnol. 2, 273 (2007).

${ }^{5}$ R. M. Olson and M. S. Gordon, J. Chem. Phys. 126, 214310 (2007).

${ }^{6}$ P. Koskinen, H. Hakkinen, B. Huber, B. v. Issendorff, and M. Moseler, Phys. Rev. Lett. 98, 015701 (2007).

${ }^{7}$ P. Pyykkö, Inorg. Chim. Acta 358, 4113 (2005).

${ }^{8}$ A. A. Herzing, C. J. Kiely, A. F. Carley, P. Landon, and G. J. Hutchings, Science 321, 1331 (2008).
}

${ }^{9}$ K. J. Taylor, C. L. Pettiettehall, O. Cheshnovsky, and R. E. Smalley, J. Chem. Phys. 96, 3319 (1992).

${ }^{10}$ F. Furche, R. Ahlrichs, P. Weis, C. Jacob, S. Gilb, T. Bierweiler, and M. M. Kappes, J. Chem. Phys. 117, 6982 (2002).

${ }^{11}$ P. Weis, Int. J. Mass Spectrom. 245, 1 (2005)

${ }^{12}$ A. Fielicke, A. Kirilyuk, C. Ratsch, J. Behler, M. Scheffler, G. von Helden, and G. Meijer, Phys. Rev. Lett. 93, 023401 (2004).

${ }^{13}$ P. Gruene, D. M. Rayner, B. Redlich, A. F. G. van der Meer, J. T. Lyon, G. Meijer, and A. Fielicke, Science 321, 674 (2008).

${ }^{14}$ X. Xing, B. Yoon, U. Landman, and J. H. Parks, Phys. Rev. B 74, 165423 (2006).

${ }^{15}$ P. Pyykkö, Chem. Rev. (Washington, D.C.) 88, 563 (1988).

${ }^{16}$ P. Pyykkö, Angew. Chem., Int. Ed. 43, 4412 (2004).

${ }^{17}$ U. Landman, Proc. Natl. Acad. Sci. U.S.A. 102, 6671 (2005).

${ }^{18}$ H. Häkkinen, M. Moseler, and U. Landman, Phys. Rev. Lett. 89, 033401 (2002).

${ }^{19}$ H. Häkkinen, B. Yoon, U. Landman, X. Li, H. J. Zhai, and L. S. Wang, J. Phys. Chem. A 107, 6168 (2003).

${ }^{20}$ S. Gilb, K. Jacobsen, D. Schooss, F. Furche, R. Ahlrichs, and M. M. Kappes, J. Chem. Phys. 121, 4619 (2004).

${ }^{21}$ M. P. Johansson, A. Lechtken, D. Schooss, M. M. Kappes, and F. Furche, Phys. Rev. A 77, 053202 (2008).

${ }^{22}$ W. Huang and L. S. Wang, Phys. Rev. Lett. 102, 153401 (2009).

${ }^{23}$ L. Ferrighi, B. Hammer, and G. K. H. Madsen, J. Am. Chem. Soc. 131, 10605 (2009).

${ }^{24}$ M. Mantina, R. Valero, and D. G. Truhlar, J. Chem. Phys. 131, 064706 (2009).

${ }^{25}$ J. Li, X. Li, H. J. Zhai, and L. S. Wang, Science 299, 864 (2003).

${ }^{26}$ S. Bulusu, X. Li, L. S. Wang, and X. C. Zeng, Proc. Natl. Acad. Sci. U.S.A. 103, 8326 (2006).

${ }^{27}$ A. Lechtken, C. Neiss, M. M. Kappes, and D. Schooss, Phys. Chem. Chem. Phys. 11, 4344 (2009).

${ }^{28}$ W. Huang, S. Bulusu, R. Pal, X. C. Zeng, and L. S. Wang, ACS Nano 3, 1225 (2009)

${ }^{29}$ M. Walter and H. Häkkinen, Phys. Chem. Chem. Phys. 8, 5407 (2006).

${ }^{30}$ D. Y. Zubarev and A. I. Boldyrev, J. Phys. Chem. A 113, 866 (2009).

${ }^{31}$ W. Huang and L. S. Wang, Phys. Chem. Chem. Phys. 11, 2663 (2009).

${ }^{32}$ R. M. Olson, S. Varganov, M. S. Gordon, H. Metiu, S. Chretien, P. Piecuch, K. Kowalski, S. A. Kucharski, and M. Musial, J. Am. Chem. Soc. 127, 1049 (2005).

${ }^{33}$ M. Diefenbach and K. S. Kim, J. Phys. Chem. B 110, 21639 (2006).

${ }^{34}$ M. B. Knickelbein and W. J. C. Menezes, Chem. Phys. Lett. 184, 433 (1991).

${ }^{35}$ M. B. Knickelbein and S. Yang, J. Chem. Phys. 93, 1476 (1990).

${ }^{36}$ D. J. Wales and H. A. Scheraga, Science 285, 1368 (1999).

${ }^{37}$ S. Yoo and X. C. Zeng, Angew. Chem., Int. Ed. 44, 1491 (2005).

${ }^{38}$ L. M. Wang, S. Bulusu, H. J. Zhai, X. C. Zeng, and L. S. Wang, Angew. Chem., Int. Ed. 46, 2915 (2007).

${ }^{39}$ L. M. Wang, R. Pal, W. Huang, X. C. Zeng, and L. S. Wang, J. Chem. Phys. 130, 051101 (2009).

${ }^{40}$ L. S. Wang, H. S. Cheng, and J. W. Fan, J. Chem. Phys. 102, 9480 (1995).

${ }^{41}$ J. Akola, M. Manninen, H. Hakkinen, U. Landman, X. Li, and L. S. Wang, Phys. Rev. B 60, R11297 (1999).

${ }^{42}$ L. S. Wang and X. Li, in Temperature Effects in Anion Photoelectron Spectroscopy of Metal Clusters in Clusters and Nanostructure Interfaces, edited by P. Jena, S. N. Khanna, and B. K. Rao (World Scientific, River Edge, 2000), p. 293.

${ }^{43}$ Y. Gao, W. Huang, J. Woodford, L. S. Wang, and X. C. Zeng, J. Am. Chem. Soc. 131, 9484 (2009).

${ }^{44}$ J. P. Perdew, K. Burke, and M. Ernzerhof, Phys. Rev. Lett. 77, 3865 (1996).

${ }^{45}$ R. A. Kendall, E. Aprà, D. E. Bernholdt, E. J. Bylaska, M. Dupuis, G. I. Fann, R. J. Harrison, J. Ju, J. A. Nichols, J. Nieplocha, T. P. Straatsma, T. L. Windus, and A. Wong, Comput. Phys. Commun. 128, 260 (2000).

${ }^{46}$ E. J. Bylaska et al., Pacific Northwest National Laboratory, Richland, Washington 99352-0999, USA (2009).

${ }^{47}$ See supplementary material at http://dx.doi.org/10.1063/1.3299292 for more information on relative energies, structures and simulated PES of four lowest-lying isomers of each cluster, and Cartesian coordinates of the two lowest-lying isomers of each cluster.

${ }^{48}$ Because the spectrum in Fig. 3(b) still contains small contributions from bands $\mathrm{X}^{\prime}, \mathrm{A}^{\prime}$, and $\mathrm{B}^{\prime}$, the subtraction method is a very approximate way to yield isomer-specific spectra. 